\title{
MELANCHOLIC SENTIMENTS TOWARDS MODULAR LEARNING MODALITY: SINGLE PARENTS IN FOCUS
}

\author{
Victoria B. Ornopia ${ }^{1}$, Ma. Melanie N. Edig ${ }^{2}$, Ronald S. Decano ${ }^{3}$ \\ ${ }^{1}$ Graduate Student, Doctor of Philosophy in Educational Management, Davao del Norte State College \\ ${ }^{2}$ Faculty, Institute of Advanced Studies, Davao del Norte State College \\ ${ }^{3}$ Dean, Institute of Advanced Studies, Davao del Norte State College
}

Article DOI: https://doi.org/10.36713/epra9175

DOI No: 10.36713/epra9175

\begin{abstract}
Schools worldwide shuttered their doors in the spring of 2020 to slow the spread of the COVID -19 pandemic virus. This physical closure quickly moved to modular learning, which increased parental and guardian responsibilities. Data were collected from 10 single parents of Rizal Memorial Colleges, Inc. The research design of this study utilized the phenomenological method to determine the Melancholic sentiments towards modular learning modality: single parents in focus in The Rizal Memorial Colleges, Inc. This study aimed to investigate parents' experiences and struggles by the use of thematic coding with the use of essential themes. Data obtained identified emergent themes clustered, namely; strive to balance parent employment demands and learner needs, strenuous assisting more than one child in the home with learning, lack of personal balance, and parent feels overwhelmed; maintaining a strict schedule; engaging in creative activities; keeping children busy and; organizing daily routine; tracking academic progress, keeping socio-emotional Development, accessing of achievement, and identifying emotional toll. The findings revealed and addressed the learning gap that has emerged in their children's learning in these challenging times. Furthermore, single parents, being aware of how to manage their time, struggles, hardship, and challenges to cope with their sentiment experiences, and strive on how they can surpass and would be a strong basis for school administrators as this comes as an opportunity to evaluate the effectiveness of different educational approaches and develop teaching and learning process suited to specific educational needs. Considering the result of this study as input from families, and should be sought to create a program and learning method that is beneficial to all school stakeholders.
\end{abstract}

KEYWORDS: Melancholic sentiments, Modular learning modality, and Single Parents-

\section{INTRODUCTION}

This physical school closure led to a rapid shift to modular learning, which placed more responsibility for learning on parents, and guardians, experiences of parents with their children during modular learning are worth examining for future policy decision making, that is why the researcher pursue to study the melancholic sentiments of single parents both father and mother towards modular learning modality amidst covid-19 pandemic, and I heard from them, different struggles of the covid-19 pandemic, challenges, and experiences in coping with the responsibility for the learning of their children, especially in the field of education was more sentiment.

A melancholic statement and hardships in teaching-learning process of their children, specifically in modular learning modality is now arise and worth it to be listened especially the concerns was to give quality education for all Filipino learners without compromising the security and safety of the all-school stakeholders (Viner et al., 2020). 
Hence, researchers wanted to pursue this study to let the melancholic sentiment of parent's to be heard. Parental involvement in their children's emotional and intellectual Development has always been critical. They act as their children's first instructors and lay the groundwork, and they must adjust to the new typical learning system, particularly in the process of learning. As the corona virus pandemic puts face-to-face learning to a halt, parents find themselves at the frontlines of education once more. In this context, my concern is single parents' melancholic sentiment towards modular learning modality. Presently, problems such as parents working from home will have additional work providing technical support or guidance from the school. It is difficult for single parents to face this situation. (Noemi Lardizabal-Dado 2020).

In today's global environment, parents have the critical responsibility of ensuring their children obtain a great education without jeopardizing their safety. Although education suffers significantly as classes are forced to lock their doors to eager students, numerous parents are stepping up to help their children as they adapt to the new set-up, which is especially difficult presently (Mertens, 2020).

In the national context, study is doing best to distinguish the effective solutions to surpass the melancholic sentiment. Therefore, it will not be easy, but with an entire community supporting the cause, DepEd, teachers, local government units, joins single parents and education advocates at the frontlines of education. The scenario mentioned above of collaboration warrants the involvement of the concerned stakeholders to possibly solve encountered predicaments as these could hamper the attainment of development goals (Sorensen's 2020).

Parents' attitudes regarding modular learning are divided. While some parents feel more connected to their child's schoolwork than others, the study revealed the most challenging and beneficial aspects of online learning for parents, with the former being keeping their children on track while completing their coursework and the latter being interactions with their child's online teachers. Additionally, schools and instructors lack enough advice for enhancing the parental involvement experience, particularly via the efficient use of technology (Goodall, 2019).

In the local context, issuance of the School Calendar and Activities for the School Year 2020-2021 was approved based on the IATF's affirmation of our suggestions. Secretary Martin Andanar recognizes our learners', parents', and teachers' concerns that attending school in August may still be unsafe in light of COVID-19. Given expected interruptions to face-to-face classrooms and the necessity for social distancing, remote learning will be a significant component of the next school year's learning delivery (Secretary Leonor Magtolis Briones, May 8, 2020).

Thus, the issue of lone parents emerges during a pandemic catastrophe, exacerbating the sad mood toward modular learning. The majority of the time, the examination of single-parent family functioning has been seen as a departure from the norm, since the standard has been established via research on the traditional nuclear family experience. The crises may foster family growth and Development in ways that the two-parent family structure does not. The strength of the single-parent family arrangement is mostly unknown. Through in-depth conversational interviews, a phenomenological study approach was employed to examine the strength within single-parent homes.

I felt that comparable research had been undertaken on gloomy attitudes toward modular learning: solitary parents in particular. This research is distinct from others in the field since there is no uniform or universal definition of parent academic participation, owing to the scope of the academic involvement concept. Additionally, there are a variety of phrases used to describe how parents assist their children and how schools assist parents in becoming more active in school. In addition to academic participation, we must examine the family-school relationship. This research additionally distinguishes itself from its locale, since the majority of the participants hail from different cities and countries.

Furthermore, this study is relative to society's current situation because parents involved in academe are more demanding and beneficial. They also provide their children with opportunities to practice and further develop what they have learned in school. This study will give an idea to the higher positions to understand the parents' situation and consider other parent factors is a kind of academic involvement conveys to children that parents are interested and invested in their Development..

For this reason, this research study should be immediately conducted to explore and understand the parent factors and explicit structure of learning melancholic sentiments towards modular learning modality: single parents in focus. This study is timely and needs to be addressed to provide proper actions and recommendations to all school stakeholders. Thus, there are a lot of challenges concerning parent factors 


\section{Research Design}

\section{METHODOLOGY}

A qualitative, phenomenological technique was used for this study in order to concentrate on the shared experiences of a specific group or person. The strategy's main objective outlined in (Creswell, 2013) is to arrive at a description of the specific phenomenon's nature. The study wishes to ascertain the gloomy feelings concerning modular education among single parents the Rizal Memorial Colleges, Inc, target.

\section{Research Locale and Sampling}

Purposive sampling was used to choose participants for this investigation. This sampling strategy necessitates that researchers be aware of the goal of their study to correctly choose and contact eligible subjects. We chose ten (10) single parents who fit the criteria. These criteria are critical in selecting the appropriate participants for the research, since they establish the study's reliability and credibility. This research was done at The Rizal Memorial Colleges, Inc., a private institution in Davao City. The school is conveniently placed in the RMC Buildings, Purok 5, Lopez Jaena\&F. Torres Streets, Poblacion District, Barangay 8-A, Davao City.

\section{Data Collection Procedure}

It was determined that melancholy attitudes about modular learning exist and have been experienced by single parents via the use of Thematic Content Analysis (TCA). Analysis of their responses was conducted. There was a constant back and forth between the researcher's subjective estimate of how significant the responses were, as well as the participants' core statements. Meanwhile, a transcription of the interview notes will be completed immediately. For each of the questions, the researcher will look for patterns in the responses. During this step, the researcher will do a thematic analysis of the collected data.

\section{RESULTS AND DISCUSSION}

Melancholic feelings expressed by single parents regarding modular learning mode, as well as the issue of school closure and the difficulty of balancing obligations, were the first worries for the participants. The most important subject discussed is that of balancing the responsibilities of a parent's job with the requirements of their children, as well as the exhaustion of aiding several children in the house with their education. There was a lot of anxiety among the participants about the conflicting demands on their limited time and energy.

Participants frequently expressed the concern for various responsibilities competing for the limited resources of time and energy. The essential theme mentioned is: strive to balance parent employment demands and learner needs, strenuous assisting more than one child in the home with learning, lack of personal balance, and parent feeling overwhelmed. One participant cited the number of resources to be an overwhelming factor: "Feeling overwhelmed as a parent with the number of resources offered.

I was considered also the essential themes, the occurrence of school closure and modular learning modality, presented on how single parents cope their sentiments experiences, like struggles, hardship and challenges the first essential theme are as follows: challenges of single parents merged to the essential theme are as follows: maintaining a strict schedule; engaging in creative activities; keeping children busy and; organizing daily routine. The concern for various strategies was competing for the theme entails the following essential theme or sub-themes.

Parents in Davao City would then lead their children to finish their courses at home. This is the parental education option. Apart from viewing this as a means of ensuring their children's safety, they see it as a chance to strengthen their relationship with their children. This institution is making every effort to identify the most successful method for implementation in each school.

Following a set schedule religiously. In order to better understand how the respondents dealt with their emotional experiences, such as adversity, difficulty, and problems, the researcher evaluated their narratives. This research focused on the importance of adhering to a rigorous schedule, since parents throughout the globe are worried about how their children's daily routines are interrupted.

\section{Engaging in Different Creative Activities}

The researcher investigated the respondents' narratives in light of the second study question, which focused on how people deal with their subjective experiences, such as hardships, difficulty, and obstacles associated with implementing school closures. Parents agree that the lockdown has resulted in apparently endless time. This may be 
a once-in-a-lifetime chance to experiment with new things and ideas while focusing on the main topic of participating in various creative activities.

Keeping Children Involved. While parents make every effort to keep their children interested in meaningful activities, they know that there are certain obstacles. Numerous youngsters see this time as a break from school and want nothing to do with a typical school-like schedule. Rather than that, they prefer to sleep and wake up when they like and spend the remainder of their day playing video games and watching cartoons/movies.

Parents expressed their displeasure at the unexpected shutdown of their children's schools and expressed worry over their children's daily routines. Parents had the impression that most days of the week were governed by a rigid schedule imposed by the educational establishment. Students may learn the importance of keeping track of their time, organizing their days, and finishing their work on time this way.

I merged with the third researcher questions of this study the following essential theme presented: Tracking Academic Progress, Keeping socio- emotional Development, Accessing of achievement, and Identifying emotional toll. Parents revealed a concern for quality or quantity of content and/or general concern about the rigor of the modular learning modality. Tracking Academic Progress second participants described concern about a student making adequate progress or being fully prepared for the future.

\section{Keeping socio- emotional Development}

As I analyzed their narrations, the participants expressed their ideas. An equal number of single parent's participants described concern for the socio-emotional Development as those that described an academic progress concern. Accessing of achievement

The third identified essential theme is accessibility of achievements. As I analyzed their narrations. Many participants described barriers preventing students from fully engaging with the modular learning opportunities. Identifying Emotional Toll. As I analyzed their narrations, parents' significant emotional toll because of supporting students during modular learning modality/ learning at home was coded into an essential theme within, which are the learning outcomes.

\section{IMPLICATIONS FOR FUTURE DIRECTION}

According to the data, single parents were most concerned about the difficulties their children would face as a result of unexpected school closings and a ban on all social events. There was a lot of discussion in opinion pieces and alerts about the decline in educational opportunities and the resulting effects on pupils. The whole country and academics throughout the globe have lent their support to the modular learning paradigm known as learning at home.

After analyzing the data, three key themes emerged: For starters, parents report that they struggle to strike a balance between their professional obligations and their children's educational requirements, that they lack personal balance, and that they feel overburdened. Second, set of essential themes maintaining a strict schedule; engaging in creative activities; difficulties faced in keeping children busy, and impact on the daily routine, and lastly, third set four essential themes: academic progress; socio-emotional Development; accessibility of achievement; and significant emotional toll, this has become a tough routine for the single parents working.

\section{Implications}

Researcher analyzed from the different information and scenarios of real situations to participants responses, with the help of analyst and researcher adviser. That results of this study were cleared and directed to the future directions of the study implied that many students' special learning needs were left unmet due to the lack of capacity.

Single parent expressed melancholic sentiments toward modular learning modality, their struggles, hardship, and challenges on how they can surpass with the two activities, like teaching their children with the modular learning modality and daily ventures for putting foods on their table as a single parents, the demands of time they need to exert an extra efforts as parents,' teachers, and breadwinner. Being single parent and direct teacher or knowledge provider in the certain topic, without preparation on how to inculcate the knowledge to their children on how to help their children in learning under over fatigue physically and mentally drain.

These are difficult times for mankind in general, particularly for growing brains. To alleviate physical and mental health implications, the government, non-governmental organizations (NGOs), schools, and parents must establish a framework through consistent routines, communication, and new partnerships. Although the literature continuously expands, certain lessons may be drawn from prior epidemics that impacted everyone. Home or 
modular learning has developed as a viable alternative to traditional education approaches that should be optimized to teach children fundamental learning skills at home with little resources.

Schools have played a huge role in rethinking the traditional approach of teaching and learning in order to meet these difficulties. Even though they've given instructors the tools they need to get started with online learning, they haven't given up on getting parents and kids to join in.

It was necessary to conduct feasibility testing, quality control, and regulation before implementing the tactics outlined above in the long-term. This is why it is necessary for the government or school administration to set up monitoring organizations. Adjustments should be made to the present educational budget so that these educational changes may be implemented in times of crisis. Even yet, things haven't always been that simple.

Moreover, conventional communication methods with single parents included circulars and notes in diaries. Few schools have short messaging services and messenger or email communication channels with parents. While those few schools that seem to have utilized technology as best as possible the seamless communications to parents via videos, graphics, online guides, and support, it was a first time and a unique challenge for many schools. They may have to evaluate how effective their outbound communication has been and whether parents and students can get the help they intend to give in the first place.

\section{Future Directions}

As a consequence of this research, school administrators will have a solid foundation on which to build their hybrid model of teaching and learning that is tailored to meet the requirements of individual students. For a learning environment that benefits everyone, families should be consulted.

Principal. The results may provide the school principal and administration with reliable bases in improving their supervisory services.

Rizal Memorial Colleges, Inc. The results of this study can be used as a basis for enhancing the educational systems on developing the new normal learning modalities for the single parents and students for the quality education in general, and propose a program to develop the learning and educational capability of Filipino single parents that it can use any time for their family.

Teachers. A better understanding of the strengths and limitations of single parents in their care and education would inspire them to commit more time and effort to aiding these families, with the help of their superiors. These teachers emphasize enabling parents' curiosity, preferring to provide parents the opportunity for self-directed learning and allowing parents to participate actively in educational events.

Single parents. For the awareness on how to manage their time, struggles, hardship, and challenges to cope with their sentiment experiences and how they can surpass. The strengths manifested from this study serve in recognizing their efforts, thus motivating the parent to gain effective skills in helping their children's learning at home or so-called modular learning modality. Also, it can be used for parents who live in remote areas that have no reception can still empower their children using education through alternative options like modular learning, and they are willing and able to guide their children in learning.

Students, as the direct transmission view of learning, or recipient of the outputs of this study.

Lastly, Future researchers. This study may be a reference for future researchers if they have to venture this kind of research.

\section{ACKNOWLEDGEMENT}

I, Victoria B. Ornopia, would like to express my profound thanks and gratitude to the following individuals for their invaluable contributions to accomplishing this work. For his support to complete this study, Dr. Ronald Decano, research advisor and Dean of Davao del Norte State College's Graduate School. The examiners panel provided useful remarks and ideas that assisted me in significantly enhancing my article. To Dr. Mark Van M. Buladaco, who assisted me in completing and submitting this article for publication. Additionally, I'd want to express my gratitude to my parents and friends for their inspiration and support. To my instructors' responders who made it possible for this book to be completed in such a short period. Finally, and most significantly, I would want to express my gratitude to our almighty God for providing the direction and strength necessary to accomplish this huge task. 


\section{REFERENCES}

1. Ali, N. (2020). Students disappointed with online teaching system amid COVID-19. Retrieved from https://dailytimes.com.pk/587446/students-disappointed-withonline-teaching-system-amid-covid-19/

2. Chang, G. C., \& Yano, S. (2020). How are countries addressing the Covid-19 challenges in education? A snapshot of policy measures.

3. Hasan, S. (2020). Schools close, children free -parents face a new conundrum.

Retrieved from https://www.dawn.com/news/1540682/schools-close-children-free-parentsface-new-conundrum

4. Jinshan, H. (2020). Parents grapple with e-learning as Chinese schools stay

shut. Retrieved from https://www.thestar.com.my/tech/tech-news/2020/02/24/parents-grapplewith-e-learning-aschinese-schools-stay-shut

5. Lynch, (2018). Principles and Methods of Teaching. $2^{\text {nd }}$ edition, Manila: Carlos P. Garcia Publishing Company.

6. Look'e P. (2017). Cooperative Learning: Teacher's Differences through Cooperation. New York: McGraw-Hill Book Company.

7. Razzaque, A. (2020). School's out. Retrieved from https://www.thenews.com.pk/ print/621813-school-s-out

8. Salas, B. (2013). Pedagogy in Teaching Learning. Quezon City: Publishing Company Incorporated.

9. Sandoval, J. et.al.(2017). New Design for Elementary Curriculum and Instruction. $2^{\text {nd }}$ edition, New York: McGraw Hill Book Company.

10. Secretary Leonor Magtolis Briones (May 8, 2020)-At the IATF Meeting presented the highlights of the draft Basic Education Learning Continuity Plan (BE-LCP), and the DepEd's decision on the date of the school opening for SY 2020-2021.Smith, W. (2016).The Role of Modern Teacher. New York: Mcmillan Company.

11. Solis, Miguela M. \& Florencio P. Fresnoza.(2018). Fundamental Principles of Teaching and Learning for Better Living. Quezon City. Eagle Publishing.

12. UNESCO. (2020). COVID-19 Educational disruption and response. Retrieved from https://en.unesco.org/themes/education-emergencies/coronavirus-school-closures 